\title{
Long-term physical activity leads to a significant increase in serum SRAGE levels: a sign of decreased AGE-mediated inflammation due to physical activity?
}

\author{
Michael Sponder ${ }^{1}$ (1) $\cdot$ loana-Alexandra Campean ${ }^{1} \cdot$ Michael Emich $^{2} \cdot$ Monika Fritzer-Szekeres $^{3} \cdot$ Brigitte Litschauer $^{4}$. \\ Senta Graf ${ }^{1}$ - Daniel Dalos ${ }^{1}$. Jeanette Strametz-Juranek ${ }^{1}$
}

Received: 7 September 2017 / Accepted: 19 January 2018 / Published online: 24 January 2018

(c) The Author(s) 2018. This article is an open access publication

\begin{abstract}
There is growing evidence that low levels of the circulating soluble receptor of advanced glycation end products (sRAGE) are a valuable predictor of cardiovascular disease (CVD). The aim of this prospective study was to investigate the influence of long-term physical activity on serum sRAGE levels. 109 subjects were recruited, and 98 completed the study. Participants were asked to perform exercise within the calculated training pulse for 8 months. The performance gain was measured/ quantified by bicycle stress tests at the beginning and end of the observation period. sRAGE was measured at baseline and after 2/6/8 months by ELISA. Backwards, multiple linear regression analysis was performed to investigate the association of co-variables age, sex, BMI, and performance at baseline, $\mathrm{HbA}_{1} \mathrm{c}$, and lipoprotein a with baseline sRAGE levels. We identified BMI and lipoprotein a as significant predictors for baseline sRAGE levels. Compared to subjects with a performance gain $\leq 4.9 \%$ subjects with a gain $>5 \%$ showed a significant increase in sRAGE levels up to $22 \%$. sRAGE serum levels correlate negatively with lipoprotein a levels and BMI and long-term physical activity leads to a significant increase in serum sRAGE levels (9-22\%), whereby the sRAGE increase is most pronounced in subjects with initially low-performance levels, suggesting that in particular, these subject profit the most from increased physical activity. The sport-mediated increase of sRAGE might be a sign of decreased AGE-mediated inflammation and highlight the protective effect of sports on CVD and other disease which are at least partly mediated by an increased inflammation status.
\end{abstract}

Clinical trials registration NCT02097199.

Keywords sRAGE $\cdot$ RAGE $\cdot$ Advanced glycation end products $\cdot$ Physical activity $\cdot$ Inflammation

$\begin{array}{ll}\text { Abbreviations } \\ \text { AGE } & \text { Advanced glycation end products } \\ \text { ALAT } & \text { Alanine aminotransferase } \\ \text { ASAT } & \text { Aspartate aminotransferase } \\ \text { BMI } & \text { Body mass index }\end{array}$

Michael Sponder

michael.sponder@meduniwien.ac.at

1 Department of Cardiology, Medical University of Vienna, Währinger Gürtel 18-20, 1090 Vienna, Austria

2 Austrian Federal Ministry of Defence and Sports, Austrian Armed Forces, Brünnerstraße 238, 1210 Vienna, Austria

3 Department of Medical and Chemical Laboratory Analysis, Medical University of Vienna, Währinger Gürtel 18-20, 1090 Vienna, Austria

4 Department of Pharmacology, Medical University of Vienna, Währinger Gürtel 18-20, 1090 Vienna, Austria
CABG Coronary artery bypass graft

CHD Chronic heart disease

CV Coefficient of variation

CVD Cardiovascular disease

DBP Diastolic blood pressure

ELISA Enzyme-linked immunosorbent assay

GT Glutamyl transferase

hsCRP High-sensitivity C-reactive protein

IL Interleukin

LDH Lactate dehydrogenase

MAPKs Mitogen-activated protein kinases

MI Myocardial infarction

MMP Matrix metalloproteinases

NF-кB Nuclear factor kappa B

PCI Percutaneous coronary intervention

PI3-K Phosphatidylinositol-3 kinase

RAGE Receptor for advanced glycation end products

SBP Systolic blood pressure 
SD Standard deviation

sRAGE Soluble receptor of advanced glycation end products

\section{Introduction}

Advanced glycation end products (AGEs) have been associated with the prevalence of numerous disease, e.g., diabetes and its vascular complications [1], Alzheimer's disease [2], and atherosclerosis [3]. The circulating soluble receptor of advanced glycation end products (sRAGE) is a biomarker reflecting RAGE (receptor for advanced glycation end products) activity. sRAGE levels were shown to be elevated after acute myocardial infarction (MI) [4], but lower levels of sRAGE are independently associated with incident coronary heart disease, diabetes mellitus, metabolic syndrome, heart failure, and death [5-7]. There is growing evidence that low sRAGE levels are a valuable predictor of cardiovascular disease. The investigation of the influence of long-term physical activity on biomarkers for calcification processes [8], inflammation [9] or the lipid profile [10, 11], inter alia by our group, has already delivered important information; however, the impact of long-term physical activity on sRAGE levels is mostly unknown and available data is conflicting $[12,13]$. Therefore, it was the aim of the present prospective study to investigate the influence of 8 months of increased physical activity on serum sRAGE levels.

\section{Methods}

In total, 109 subjects were recruited. The inclusion criteria were: age between 30 and 65 years and physical ability to perform endurance exercise. Exclusion criteria were: age $<30$ or $>65$ years, no ability to perform endurance exercise, current oncologic or infectious disease (anamnestic or increased inflammation parameters at baseline). 11 subjects did not complete the study for different reasons (accidents, loss of motivation, etc.). Finally, 98 subjects completed the study. The study population, therefore, consisted of 38 female and 60 male subjects aged 30-65 years with at least one classic cardiovascular risk factor: overweight $\left(\mathrm{BMI}>25.0 \mathrm{~kg} / \mathrm{m}^{2}\right)$, hypertension $(\mathrm{SBP}>140 \pm \mathrm{DBP}>85 \mathrm{mmHg}$ at rest/antihypertensive medication), hyper/dyslipidemia (anamnestic statin therapy), diabetes mellitus (HbA1c $>6.5$ rel\%/DM medication), current smoking, known CHD [anamnestic MI, PCI (percutaneous coronary intervention), CABG (coronary artery bypass graft), stroke], and positive family anamnesis for MI/CVD/ stroke of mother and/or father. The anamnestic weekly alcohol intake was measured in units: 1 unit corresponds to 0.331 beer, $0.1251 \mathrm{red} /$ white wine, or 0.021 spirits.
The study was carried out in adherence to the Declaration of Helsinki and its later amendments and the ethical standards in sports and exercise science research [14]. The protocol has been approved by the Ethical Commission of the Medical University of Vienna (EC-number: 1830/2013) and informed consent was obtained from all subjects before inclusion.

\section{Measurement of anthropometric data and bicycle stress test (ergometry)}

After detailed anamnesis and physical examination including the measurement of height, weight, body water, body muscle mass, and body fat (with a diagnostic scale, Beurer BG 16, Beurer GmbH, Ulm, Germany), the subjects had to perform a bicycle stress test (ergometry) at the beginning of the study to define their performance level and to calculate their individual training pulse/target heart rate (using the Karvonen formula with an intensity level of $65-75 \%$ for moderate and $76-93 \%$ for vigorous intensity). The subjects were let to decide the kind of physical activity/sports; however, they were asked to perform at least $75 \mathrm{~min} /$ week of vigorous or $150 \mathrm{~min} /$ week of moderate intensity endurance training (or a mixture; strength training was allowed but not mandatory) within the calculated training pulse. A second ergometry was performed at the end of the study (after 8 months) to prove and also quantify exactly and objectively the change/gain in performance. Therefore, we relinquished the leading of a training protocol. The bicycle stress tests were always ECG-monitored and performed with the same system (Ergometer eBike comfort, GE Medical Systems, Freiburg, Germany) starting with $25 \mathrm{~W}$ and increasing every 2 min by $25 \mathrm{~W}$ (according to the protocol of the Austrian Society of Cardiology which is equal to the guidelines of the European Society of Cardiology). Blood pressure and heart rate were taken every $2 \mathrm{~min}$. Subjects were told to cycle with 50-70 revolutions/min until exhaustion occurred. The target performance was calculated using body surface [calculated according to DuBois formula [15]: body surface $\left(\mathrm{m}^{2}\right)=0.007184 \times$ height $(\mathrm{cm})^{0.725} \times$ weight $(\mathrm{kg})^{0.425}$ ] [15], sex and age: for men: performance $(\mathrm{W})=6773+136,141 \times$ body surface $-0.916 \times$ body surface $\times$ age.

For women: performance $(\mathrm{W})=3933+86,641 \times$ body surface $-0.346 \times$ body surface $\times$ age.

An individual target performance of $100 \%$ represents the performance of an untrained collective. We estimate that a performance gain of at least $5 \%$ is necessary to manifest measurable and clinically relevant changes concerning the inflammation profile. Therefore, the study population was divided into 4 groups according to the baseline performance and to the performance gain over the observation period: 
- Group 1 consists of participants with a performance $\leq 99 \%$ at baseline and a performance gain $\leq 4.9 \%$.

- Group 2 of participants with a performance $\leq 99 \%$ at baseline and a performance gain $>5 \%$.

- Group 3 of participants with a performance $>100 \%$ at baseline and a performance gain $\leq 4.9 \%$.

- Group 4 of participants with a performance $>100 \%$ at baseline and a performance gain $>5 \%$.

\section{Routine laboratory and SRAGE analysis}

Blood samples were drawn in a not starving state. Blood samples for the determination of sRAGE (CycLex Co human sRAGE ELISA Kit, CY-8083 Nagano, Japan) were taken at baseline, after 2, 6, and 8 months and analysed by ELISA (enzyme-linked immunosorbent assay) according to the manufacturer's instruction. The coefficient of variation (CV) was $6.9 \%$. All blood samples were taken after 10 min of still lying from an arm vein with a tube/adapter system. Samples for the determination of routine laboratory parameters were analysed immediately after drawing. The analysis was performed according to the manufacturer's instructions.

\section{Statistical analysis}

Statistical analysis was accomplished using SPSS 20.0. Continuous and normally distributed data are described by mean \pm standard deviation (SD). Non-normally distributed data are described by median/25th quartile/75th quartile. Single correlations involving only two normally distributed data were calculated using Pearson Correlation, single correlations involving two non-parametric data and/or ordinal data were calculated using Spearman's rho analysis. To investigate the correlation of sRAGE levels with anthropometric data and laboratory parameters, we used Spearman's rho analysis. Backwards, multiple linear regression analysis was performed to investigate the association of the co-variables age, sex, T2DM, smoking, BMI, performance gain, $\mathrm{HbA}_{1} \mathrm{c}$ and lipoprotein a with both baseline sRAGE levels and sRAGE levels after 8 months of physical activity.

As it was expected that not all of the subjects would reach an adequate performance gain during the observation period, we defined in the forefront a minimum threshold of 5\% performance gain as significant and divided the study population into the 4 mentioned groups. To investigate trends over the observation period of 8 months, we used the Friedman test. All tests were performed in accordance with two-sided testing and $p$ values $\leq 0.05$ were considered significant.

\section{Results}

\section{Risk factor profile, anthropometric, and laboratory data at baseline}

Risk factor profile, anthropometric, and laboratory data for the four groups at baseline are shown in Table 1. Concerning the total population, the most prevalent cardiovascular risk factors were overweight/adipositas $(65.3 \%)$, a positive family anamnesis (44.9\%), hypertension (32.7\%), and smoking $(20.4 \%)$. Compared to the initially non-sportive groups $1+2$, participants of the initially sportive groups, $3+4$ had significantly higher body muscle mass and body water and lower body fat amount $(35.6 \pm 3.9$ vs. $33.5 \pm 3.9 \%$, $p=0.014 ; 54.1 \pm 6.1$ vs. $49.9 \pm 4.5 \%, p<0.001$; $27.5 \pm 10.9$ vs. $32.1 \pm 6.2 \%, p=0.018)$. There was no significant difference in BMI $(28.3 \pm 5.0$ vs. $26.9 \pm 3.4 \mathrm{~kg} /$ $\mathrm{m}^{2}$ ). The performance gain was $-0.4 \pm 4.6 \%$ in group $1,13.7 \pm 6.7 \%$ in group $2,-2.2 \pm 5.3 \%$ in group 3 , and $13.4 \pm 4.9 \%$ in group 4 .

Concerning the total population, at baseline, sRAGE levels correlated positively with chloride $(p=0.039)$ and anorganic phosphate $(p=0.049)$ and negatively with BMI $(p=0.006)$, erythrocyte count $(p=0.018)$, haemoglobin $(p<0.001)$, haematocrit $(p=0.001)$, ALAT $(p=0.019)$, apolipoprotein B $(p=0.037)$, and lipoprotein a $(p=0.006)$. Concerning other anamnestic, anthropometric, and laboratory parameter, there was no correlation; in particular, sRAGE levels did not correlate with smoked pack years $(p=0.727)$, weekly alcohol intake $(p=0.760)$, age $(p=0.323)$, hsCRP $(p=0.540)$, interleukin-6 $(p=0.145)$, $\operatorname{HbA}_{\mathrm{c}}(p=0.284)$, and C-peptide $(p=0.079)$. Backwards, multiple linear regression analysis was performed to investigate the association of the co-variables age, sex, BMI, performance gain, $\mathrm{HbA}_{1} \mathrm{c}$, and lipoprotein a with baseline sRAGE levels. We identified BMI and lipoprotein a as (borderline) significant predictors for baseline sRAGE levels and also sRAGE levels after 8 months of physical activity, as shown in Table 2 (baseline: $F=6.08 ; p<0.005 ; r_{\text {adj }}^{2}=0.10$; after 8 months of physical activity: $F=4.63 ; p<0,012$; $\left.r_{\text {adj }}^{2}=0.07\right)$.

\section{Influence of physical activity on sRAGE levels}

There was no significant difference concerning baseline sRAGE and hsCRP levels for group $1+2$ vs. group $3+4$ ( $p=0.172$ and 0.077$)$, but there was a significant difference for IL-6 $(p=0.020)$. The sRAGE levels at the different points of measurement of the four groups are shown in Table 3. The initially sportive participants (group $3+4$ ) showed higher sRAGE levels at baseline compared to the 
Table 1 Description of population

\begin{tabular}{|c|c|c|c|c|c|}
\hline & \multicolumn{2}{|c|}{ Initially non-sportive $(n=37)$} & \multicolumn{2}{|c|}{ Initially sportive $(n=61)$} & \multirow{2}{*}{$\begin{array}{l}p \text { value Group } 1+2 \\
\text { vs. } 3+4\end{array}$} \\
\hline & Group $1(n=14)$ & Group $2(n=23)$ & Group $3(n=27)$ & Group $4(n=34)$ & \\
\hline Hypertension & $n=6 / 42.9 \%$ & $n=11 / 40.7 \%$ & $n=7 / 30.4 \%$ & $n=8 / 23.5 \%$ & \\
\hline Dyslipidaemia & $n=4 / 28.6 \%$ & $n=7 / 25.9 \%$ & $n=8 / 34.8 \%$ & $n=10 / 29.4 \%$ & \\
\hline Diabetes mellitus & $n=2 / 14.2 \%$ & $n=0 / 0 \%$ & $n=1 / 4.3 \%$ & $n=1 / 2.9 \%$ & \\
\hline Overweight/adipose & $n=10 / 71.5 \%$ & $n=18 / 66.6 \%$ & $n=16 / 69.6 \%$ & $n=20 / 58.9 \%$ & \\
\hline Ex-smoking & $n=5 / 35.7 \%$ & $n=11 / 40.7 \%$ & $n=14 / 60.9 \%$ & $n=12 / 35.3 \%$ & \\
\hline Smoking & $n=6 / 42.9 \%$ & $n=7 / 25.9 \%$ & $n=3 / 13.0 \%$ & $n=4 / 11.8 \%$ & \\
\hline Known CHD/stroke & $n=1 / 7.1 \%$ & $n=5 / 18.5 \%$ & $n=2 / 8.7 \%$ & $n=8 / 23.5 \%$ & \\
\hline Family anamnesis & $n=7 / 50.0 \%$ & $n=13 / 48.1 \%$ & $n=11 / 47.8 \%$ & $n=13 / 38.2 \%$ & \\
\hline Alcohol (units/week) & $1.3 \pm 1.7$ & $2.9 \pm 3.4$ & $2.9 \pm 3.7$ & $3.4 \pm 4.6$ & 0.483 \\
\hline Age (years) & $51 \pm 5$ & $48 \pm 8$ & $49 \pm 7$ & $49.7 \pm 5.5$ & 0.991 \\
\hline BMI $\left(\mathrm{kg} / \mathrm{m}^{2}\right)$ & $28.2 \pm 4.4$ & $28.4 \pm 5.3$ & $27.1 \pm 3.8$ & $26.8 \pm 3.1$ & 0.298 \\
\hline Body water $(\%)$ & $48 \pm 3$ & $51 \pm 5$ & $53 \pm 6$ & $55 \pm 6$ & $0.001 * *$ \\
\hline Body fat $(\%)$ & $34 \pm 4$ & $31 \pm 7$ & $28 \pm 9$ & $27 \pm 12$ & $0.002 * *$ \\
\hline Body muscle (\%) & $32 \pm 3$ & $34 \pm 4$ & $34 \pm 4$ & $36 \pm 4$ & $0.013 * *$ \\
\hline $\mathrm{SBP}(\mathrm{mmHg})$ & $130 \pm 11$ & $134 \pm 7$ & $129 \pm 16$ & $132 \pm 11$ & 0.598 \\
\hline $\mathrm{DBP}(\mathrm{mmHg})$ & $80 \pm 9$ & $78 \pm 8$ & $79 \pm 9$ & $77 \pm 7$ & 0.438 \\
\hline HR (bpm) & $68 \pm 9$ & $69 \pm 7$ & $65 \pm 9$ & $65 \pm 7$ & $0.031 * *$ \\
\hline $\begin{array}{l}\text { Performance gain } \\
(\%)\end{array}$ & $-0.4 \pm 4.6$ & $13.7 \pm 6.7$ & $-2.2 \pm 5.3$ & $13.4 \pm 4.9$ & 0.498 \\
\hline Erythrocytes (T/l) & $4.7 \pm 0.5$ & $4.8 \pm 0.4$ & $4.6 \pm 0.3$ & $4.8 \pm 0.4$ & 0.921 \\
\hline Haemoglobin (g/dl) & $13.8 \pm 1.9$ & $14.1 \pm 1.3$ & $13.7 \pm 1.0$ & $14.3 \pm 1.1$ & 0.997 \\
\hline Haematocrit (\%) & $40 \pm 5$ & $40 \pm 3.2$ & $40 \pm 3$ & $41 \pm 3$ & 0.683 \\
\hline Thrombocytes (G/l) & $271 \pm 67$ & $241 \pm 60$ & $275 \pm 68$ & $242 \pm 39$ & 0.762 \\
\hline Leukocytes (G/l) & $7.9 \pm 2.0$ & $6.4 \pm 1.5$ & $6.5 \pm 1.8$ & $6.1 \pm 1.2$ & 0.059 \\
\hline $\mathrm{Na}(\mathrm{mmol} / \mathrm{l})$ & $141 \pm 2$ & $141 \pm 1.4$ & $141 \pm 2$ & $142 \pm 2$ & 0.231 \\
\hline $\mathrm{K}(\mathrm{mmol} / \mathrm{l})$ & $4.1 \pm 0.3$ & $4.1 \pm 0.3$ & $4.3 \pm 0.2$ & $4.2 \pm 0.3$ & $0.028 * *$ \\
\hline $\mathrm{Cl}(\mathrm{mmol} / \mathrm{l})$ & $101 \pm 2$ & $101 \pm 2$ & $101 \pm 2.0$ & $101 \pm 2$ & 0.542 \\
\hline $\mathrm{Ca}(\mathrm{mmol} / \mathrm{l})$ & $2.3 \pm 0.1$ & $2.3 \pm 0.8$ & $2.3 \pm 0.8$ & $2.3 \pm 0.1$ & 0.645 \\
\hline Phosphate (mmol/l) & $1.1 \pm 0.1$ & $1.0 \pm 0.1$ & $1.1 \pm 0.2$ & $1.1 \pm 0.2$ & $0.043 * *$ \\
\hline $\mathrm{Mg}(\mathrm{mmol} / \mathrm{l})$ & $0.83 \pm 0.04$ & $0.85 \pm 0.06$ & $0.8 \pm 0.1$ & $0.8 \pm 0.1$ & 0.563 \\
\hline Creatinine (mg/dl) & $0.87 \pm 0.16$ & $0.8 \pm 0.1$ & $0.9 \pm 0.2$ & $0.9 \pm 0.2$ & $0.009^{* *}$ \\
\hline BUN (mg/dl) & $13.2 \pm 3.6$ & $20.0 \pm 26.4$ & $14.1 \pm 3.9$ & $14.1 \pm 3.7$ & 0.200 \\
\hline Uric acid (md/dl) & $5.6 \pm 2.1$ & $5.1 \pm 1.3$ & $5.3 \pm 1.5$ & $5.3 \pm 1.1$ & 0.762 \\
\hline Lipasis (U/l) & $35 \pm 12$ & $36 \pm 14$ & $42 \pm 21$ & $44 \pm 18$ & $0.005^{* *}$ \\
\hline $\begin{array}{l}\text { Cholinesterasis } \\
(\mathrm{kU} / \mathrm{l})\end{array}$ & $8.1 \pm 1.5$ & $8.4 \pm 1.7$ & $7.8 \pm 1.7$ & $8.4 \pm 1.7$ & 0.721 \\
\hline $\begin{array}{l}\text { Alkalic phosphate } \\
\text { (U/l) }\end{array}$ & $64 \pm 19$ & $71 \pm 65$ & $57 \pm 16$ & $59 \pm 14$ & 0.320 \\
\hline $\operatorname{ASAT}(\mathrm{U} / \mathrm{l})$ & $28 \pm 9$ & $23 \pm 8$ & $27 \pm 7$ & $24 \pm 5$ & 0.277 \\
\hline ALAT (U/l) & $29 \pm 15$ & $28 \pm 15$ & $26 \pm 9$ & $25 \pm 9$ & 0.728 \\
\hline Gamma-GT (U/l) & $25 \pm 15$ & $39 \pm 76$ & $21 \pm 12$ & $27 \pm 19$ & 0.709 \\
\hline LDH (U/l) & $179 \pm 27$ & $173 \pm 27$ & $175 \pm 28$ & $170 \pm 21$ & 0.656 \\
\hline
\end{tabular}

Cardiovascular risk factor profile, anthropometric data and lab-analysis at baseline of the four groups

$C H D$ chronic heart disease, $B M I$ body mass index, $S B P$ systolic blood pressure, $D B P$ diastolic blood pressure, $H R$ heart rate, $N a$ natrium, $K$ potassium, $\mathrm{Cl}$ chloride, $\mathrm{Ca}$ calcium, $\mathrm{Mg}$ magnesium, $B U N$ blood urea nitrogen, $A S A T$ aspartate aminotransferasis, $A L A T$ alanine aminotransferasis, $G T$ glutamyl transferasis, $L D H$ lactate dehydrogenasis

The $p$ values represent the significance of the differences between baseline values of the initially non-sportive groups (Group $1+2)$ vs. the initially sportive groups (Group $3+4$ ). For better recognisability the significant differences are marked $(* *)$

initially non-sportive groups (group $1+2$ ). There was no significant change in sRAGE levels in group $1(p=0.392$; $-8.3 \%)$ and group $3(p=0.184 ; 5.8 \%)$ compared to significant changes in group $2(p=0.015 ; 22.4 \%)$ and group $4(p<0.001 ; 9.3 \%)$ calculated by Friedman test. We also stated a decrease of the inflammation parameters hsCRP 
Table 2 Backwards multiple linear regression analysis
Regression coef- $\quad$ Standard error ficient $B^{\mathrm{b}}$
$T$

$\beta$

$T$

\begin{tabular}{lrllll}
\hline At baseline & & & & & \\
Constant & 578.547 & & & & \\
Lipoprotein a & -0.494 & 0.249 & -0.206 & -1.986 & 0.050 \\
BMI & -6.677 & 3.386 & -0.205 & -1.972 & 0.052 \\
$\begin{array}{l}F=6.08 ; p<0.005 ; r_{\text {adj }}^{2}=0.10 \\
\text { After 8 months }\end{array}$ & & & & \\
Constant & 630.207 & & & & \\
Lipoprotein a & -0.419 & 0.246 & -0.174 & -1.705 & 0.091 \\
BMI & -7.407 & 3.772 & -0.201 & -1.964 & 0.053 \\
$F=4.63 ; p<0.012 ; r_{\text {adj }}^{2}=0.07$ & & & & \\
\hline
\end{tabular}

Backwards multiple linear regression analysis; age, sex, smoking, T2DM, BMI, performance gain, $\mathrm{HbA}_{1} \mathrm{c}$ and lipoprotein a were inserted as co-variables but only BMI and lipoprotein a were significant predictors of baseline sRAGE levels and sRAGE levels after 8 months of physical activity

\begin{tabular}{|c|c|c|c|c|}
\hline & \multicolumn{2}{|c|}{ Initially non-sportive $(n=37)$} & \multicolumn{2}{|c|}{ Initially sportive $(n=61)$} \\
\hline & Group $1(n=14)$ & Group $2(n=23)$ & Group $3(n=27)$ & Group $4(n=34)$ \\
\hline sRAGE baseline & $339 / 258 / 380$ & $330 / 280 / 367$ & $346 / 275 / 480$ & $366 / 288 / 481$ \\
\hline sRAGE 2 months & $330 / 252 / 450$ & $375 / 285 / 437$ & $429 / 310 / 465$ & $409 / 292 / 505$ \\
\hline sRAGE 6 months & $366 / 246 / 437$ & $392 / 321 / 488$ & $424 / 316 / 543$ & $401 / 296 / 519$ \\
\hline sRAGE 8 months & $311 / 228 / 448$ & $404 / 311 / 442$ & $366 / 316 / 504$ & $400 / 322 / 489$ \\
\hline Change (\%) & -8.3 & 22.4 & 5.8 & 9.3 \\
\hline$p$ value & 0.392 & 0.015 & 0.184 & $<0.001$ \\
\hline hsCRP baseline & $0.09 / 0.05 / 0.22$ & $0.14 / 0.08 / 0.31$ & $0.11 / 0.05 / 0.23$ & $0.09 / 0.06 / 0.12$ \\
\hline hsCRP 2 months & $0.15 / 0.05 / 0.24$ & $0.13 / 0.07 / 0.26$ & $0.09 / 0.07 / 0.27$ & $0.08 / 0.04 / 0.17$ \\
\hline hsCRP 6 months & $0.07 / 0.05 / 0.21$ & $0.15 / 0.06 / 0.26$ & $0.14 / 0.05 / 0.36$ & $0.09 / 0.05 / 0.17$ \\
\hline hsCRP 8 months & $0.18 / 0.08 / 0.27$ & $0.11 / 0.05 / 0.27$ & $0.12 / 0.06 / 0.25$ & $0.07 / 0.04 / 0.11$ \\
\hline$p$ value & 0.532 & 0.076 & 0.567 & 0.113 \\
\hline IL-6 baseline & $3.2 / 1.9 / 3.6$ & $2.6 / 1.8 / 3.2$ & $1.9 / 1.5 / 3.0$ & $2.1 / 1.5 / 2.9$ \\
\hline IL-6 2 months & $2.4 / 1.7 / 2.8$ & $2.4 / 0.0 / 3.4$ & $1.7 / 1.5 / 2.3$ & $1.9 / 1.5 / 2.6$ \\
\hline IL-6 6 months & $2.1 / 1.5 / 2.9$ & $2.3 / 1.6 / 3.0$ & $2.4 / 0.8 / 3.3$ & $1.8 / 1.5 / 2.8$ \\
\hline IL-6 8 months & $2.2 / 0.8 / 3.0$ & $2.1 / 0.0 / 3.4$ & $1.7 / 0.8 / 2.4$ & $1.7 / 1.1 / 2.6$ \\
\hline$p$ value & 0.169 & 0.138 & 0.197 & 0.397 \\
\hline $\mathrm{HbA} 1_{\mathrm{c}}$ baseline & $5.8 \pm 1.0$ & $5.2 \pm 0.3$ & $5.4 \pm 0.8$ & $5.2 \pm 0.3$ \\
\hline $\mathrm{HbA} 1_{\mathrm{c}} 2$ months & $5.8 \pm 0.9$ & $5.2 \pm 2.3$ & $5.3 \pm 0.7$ & $5.2 \pm 0.3$ \\
\hline $\mathrm{HbA} 1_{c} 6$ months & $5.8 \pm 1.0$ & $5.2 \pm 0.3$ & $5.5 \pm 0.7$ & $5.2 \pm 0.3$ \\
\hline $\mathrm{HbA} 1_{\mathrm{c}} 8$ months & $5.9 \pm 0.9$ & $5.2 \pm 0.3$ & $5.4 \pm 0.5$ & $5.3 \pm 0.3$ \\
\hline$p$ value & 0.260 & 0.134 & $<0.001$ & 0.259 \\
\hline C-peptide baseline & $4.6 \pm 4.3$ & $3.6 \pm 2.7$ & $3.1 \pm 2.0$ & $3.3 \pm 2.4$ \\
\hline C-peptide 2 months & $4.1 \pm 3.7$ & $3.8 \pm 2.2$ & $3.4 \pm 1.8$ & $3.9 \pm 2.6$ \\
\hline C-peptide 6 months & $3.8 \pm 2.7$ & $4.4 \pm 2.8$ & $3.2 \pm 2.1$ & $3.6 \pm 2.2$ \\
\hline C-peptide 8 months & $4.5 \pm 4.6$ & $3.6 \pm 2.0$ & $3.1 \pm 1.5$ & $3.6 \pm 2.1$ \\
\hline$p$ value & 0.856 & 0.162 & 0.910 & 0.822 \\
\hline
\end{tabular}

Progression of sRAGE, hsCRP, Il-6, $\mathrm{HbA} 1_{\mathrm{c}}$ and C-peptide in the four groups at the four points of measurement (baseline, after 2, 6 and 8 months). Data is given as median/25th/75th percentile for non-parametric values and as mean \pm std dev for normally distributed values. The significances of the progressions $(p$ value) have been calculated using Friedman test. The change in sRAGE levels (baseline vs. value after 8 months) is also described in percent

$s R A G E$ soluble receptor of advanced glycation end products, $h s C R P$ high-sensitivity C-reactive protein, IL-6 interleukin-6 
and IL-6 in group 2 and group 4 but without statistical significance.

\section{Discussion}

We could show a negative correlation of lipoprotein and sRAGE levels at baseline and a significant physical activitymediated increase in serum sRAGE levels and the sRAGE increase was most pronounced in subjects with initially lowperformance levels. AGEs occur when reducing sugar reacts with amino acids in proteins or other macromolecules. AGEs are mainly generated via the Maillard reaction; however, they can also be formed by oxidation of glucose or peroxidation of lipids [16]. High AGEs levels have been associated with aging [17] and disease which are related to aging such as diabetes and its vascular complications [1], Alzheimer's disease [2], and atherosclerosis [3]. The interaction of AGEs with the receptor for advanced glycation end products (RAGE), a transmembrane receptor of the immunoglobulin superfamily composed of three domains which is expressed by, e.g., endothelial cells, lymphocytes, monocytes, and vascular smooth muscle cells, triggers the activation of mitogen-activated protein kinases (MAPKs) and phosphatidylinositol-3 kinase (PI3-K) leading to the activation of nuclear factor kappa B (NF-KB). Finally, NF- $\mathrm{KB}$ activation leads to a release of inflammatory cytokines like tumour necrosis factor $\alpha(\mathrm{TNF} \alpha)$, interleukin 6 (Il-6). Furthermore, a positive feedback mechanism between NF-kB and RAGE has been described [18]. Consequently, the interactions of AGEs with RAGE result in oxidative stress and the production of matrix metalloproteinases (MMPs), which cleave RAGEs and produce sRAGE [19].

sRAGE, the circulating soluble receptor of advanced glycation end products, is used as biomarker reflecting RAGE activity. sRAGE competes with RAGE by acting as a decoy receptor and may, therefore, prevent inflammatory processes [19]. sRAGE was shown to be elevated after myocardial infarction [4] and increased sRAGE levels were associated with poor in-hospital prognosis [20]. The major source of sRAGE in acute coronary syndrome (ACS) is not clear; however, Jensen et al. [21] speculate that it originates from the cardiomyocytes or the vascular cells in the damaged myocardium. Consequently, it seems that sRAGE is upregulated in current inflammatory processes (e.g., after myocardial infarction) to counteract inflammation-based damage. On the other hand, studies by Selvin et al. [5], Momma et al. [6], and Lazo et al. [7] could show that lower levels of sRAGE are independently associated with incident coronary heart disease, diabetes mellitus, metabolic syndrome, heart failure, and death. It seems that sRAGE levels are upregulated in acute settings such as myocardial infarction, but also in chronic disease, high sRAGE levels are beneficial. We could show a physical activity-mediated increase of sRAGE levels, whereby in particular, subjects with an initially low level of physical performance benefitted by an increase of up to $22 \%$. Furthermore, data from the ARIC study [22] delivered results that showed an inverse relationship of sRAGE with current inflammation markers (hsCRP, fibrinogen). However, we neither observed a positive nor a negative correlation of sRAGE with hsCRP or Il-6 at baseline.

Glucose plays an important role in sRAGE metabolism. AGEs accumulate in human tissue proteins as a result of chronic hyperglycemia, and since sRAGE levels have been negatively correlated with serum glucose [23, 24], we also analysed the $\mathrm{HbA} 1_{\mathrm{c}}$ and $\mathrm{C}$-peptide progression over the observation period. However, although groups 2 and 4 showed a significant increase in sRAGE levels, there was no change in $\mathrm{HbA}_{\mathrm{c}}$ and $\mathrm{C}$-peptide observable. However, we could show a negative correlation of lipoprotein a, a lipoprotein which is involved in the pathogeneses of vascular diseases, with sRAGE.

Studies in human dealing with the influence of long-term physical activity on AGE $[25,26]$ and sRAGE levels are rare and conflicting: Kotani et al. [12] measured serum sRAGE levels in 15 female and 15 male healthy, non-smoking Japanese volunteers (mean age 65 years) in the pre- and postphase of a 6-month interventional program and stated a significant reduction of circulating sRAGE levels. However, with 30 individuals, the sample size was very small and the training program only included monthly explanatory and motivational sessions to increase physical activity such as daily walking and to instruct on the appropriate methods. The participants were educated on how to measure their heart rates during a walking exercise in their radial arterial pulses, and recommended to perform the walking at $60 \%$ of the maximal heart rate for at least $\geq 30$ min. Choi et al. [13] investigated the influence of physical activity on sRAGE in 75 female non-smoking patients (mean age 55 years) suffering diabetes mellitus. They performed a bicycle stress test at the beginning of the study and the 12-week-exercise program (the subjects were assigned to walk for $60 \mathrm{~min}$ per session, five times per week at moderate exercise capacity) was monitored by a multirecord accelerometer. This study group finally observed a significant increase of circulating sRAGE levels.

It is known for a long time that physical activity is one of the most potent therapeutic intervention to prevent CVD or at least to retard its progression. The activation of the AGE-RAGE axis results in the generation of inflammatory cytokines and oxidative stress. However, low sRAGE levels have been associated with coronary heart disease, diabetes mellitus, metabolic syndrome, heart failure, and death, because sRAGE acts as decoy for RAGE ligands and thus has cytoprotective effects. The increase of serum sRAGE levels in sporting individuals might be a sign of a physical 
activity-derived decrease in AGE/RAGE-mediated inflammation and might partly be involved in the protective effect of sports on the vasculature. However, although the chosen inflammation parameters (IL-6, hsCRP) decreased in the both groups with proven performance gain (and increasing sRAGE levels), the decrease of the inflammation parameters was not significant, probably due to the low inflammation level at baseline.

\section{Conclusion}

sRAGE serum levels correlate negatively with lipoprotein a levels and BMI and long-term physical activity leads to a significant increase in serum sRAGE levels (9-22\%), whereby the sRAGE-increase is most pronounced in subjects with initially low-performance levels, suggesting that in particular, these subjects profit the most from increased physical activity. The sports-mediated increase of sRAGE might be a sign of decreased AGE-mediated inflammation and highlight the protective effect of sports on CVD and other disease which are at least partly mediated by an increased inflammation status.

\section{Limitations}

The present study has several limitations: First, although 98 participants completed the study the number of subjects is too low to show sex-specific differences. Second, several other not controlled influences and circumstances (besides physical activity) might have led to an increase in sRAGE levels.

\begin{abstract}
Acknowledgements Open access funding provided by Medical University of Vienna. We give special thanks to Heidi Kieweg, Alexander Deli, Maximilian Eisserer, Hans Riedmann, Andreas Rupp, Inkar Asanova and Klaus Koska for their support. The present study has been funded by means of the Medical University of Vienna, Austria and the Federal Ministry of Defence and Sports, Austria.
\end{abstract}

Author contributions MS: study design, clinical investigation, performing bicycle stress tests/follow-up, statistical analysis, and manuscript preparation. I-AC: clinical investigation, performing bicycle stress tests/follow-up. ME: study design. MF-S: laboratory analysis. BL: statistical analysis. SG: clinical investigation, performing bicycle stress tests/follow-up. DD: bicycle stress tests, statistics, manuscript preparation. JS-J: study design, manuscript preparation.

Funding The present study has been funded by means of the Medical University of Vienna, Austria and the Federal Ministry of Defence and Sports, Austria.

\section{Compliance with ethical standards}

Conflict of interest The authors have no conflict of interest.

Open Access This article is distributed under the terms of the Creative Commons Attribution 4.0 International License (http://creativecommons.org/licenses/by/4.0/), which permits unrestricted use, distribution, and reproduction in any medium, provided you give appropriate credit to the original author(s) and the source, provide a link to the Creative Commons license, and indicate if changes were made.

\section{References}

1. Jakus V, Rietbrock N (2004) Advanced glycation end-products and the progress of diabetic vascular complications. Physiol Res 53(2):131-142

2. Shuvaev VV, Laffont I, Serot JM, Fujii J, Taniguchi N, Siest G (2001) Increased protein glycation in cerebrospinal fluid of Alzheimer's disease. Neurobiol Aging 22(3):397-402

3. Zieman S, Kass D (2004) Advanced glycation end product crosslinking: pathophysiologic role and therapeutic target in cardiovascular disease. Congest Heart Fail 10(3):144-149 (quiz 150-151)

4. Cai XY, Lu L, Wang YN, Jin C, Zhang RY, Zhang Q, Chen QJ, Shen WF (2011) Association of increased S100B, S100A6 and $\mathrm{S} 100 \mathrm{P}$ in serum levels with acute coronary syndrome and also with the severity of myocardial infarction in cardiac tissue of rat models with ischemia-reperfusion injury. Atherosclerosis 217(2):536-542

5. Selvin E, Halushka MK, Rawlings AM, Hoogeveen RC, Ballantyne CM, Coresh J, Astor BC (2013) sRAGE and risk of diabetes, cardiovascular disease, and death. Diabetes 62(6):2116-2121

6. Momma H, Niu K, Kobayashi Y, Huang C, Chujo M, Otomo A, Tadaura H, Miyata T, Nagatomi R (2014) Higher serum soluble receptor for advanced glycation end product levels and lower prevalence of metabolic syndrome among Japanese adult men: a cross-sectional study. Diabetol Metab Syndr 6(1):33

7. Lazo M, Halushka MK, Shen L, Maruthur N, Rebholz CM, Rawlings AM, Hoogeveen RC, Brinkley TE, Ballantyne CM, Astor BC, Selvin E (2015) Soluble receptor for advanced glycation end products and the risk for incident heart failure: the Atherosclerosis Risk in Communities study. Am Heart J 170(5):961-967

8. Sponder M, Fritzer-Szekeres M, Marculescu R, Litschauer B, Strametz-Juranek J (2016) Physical inactivity increases endostatin and osteopontin in patients with coronary artery disease. Heart Vessels 31(10):1603-1608

9. Sponder M, Campean IA, Emich M, Fritzer-Szekeres M, Litschauer B, Bergler-Klein J, Graf S, Strametz-Juranek J (2017) Long-term endurance training increases serum cathepsin $\mathrm{S}$ and decreases IL-6 and hsCRP levels. J Sports Sci 35(21):2129-2134

10. Sponder M, Campean IA, Dalos D, Emich M, Fritzer-Szekeres M, Litschauer B, Bergler-Klein J, Graf S, Strametz-Juranek J (2017) Influence of long-term physical activity on PCSK9, HDL/LDL-C and $\mathrm{Lp}(\mathrm{a})$ - a prospective observational trial. Pol Arch Intern Med 127(7-8):506-511

11. Sponder M, Kopecky C, Campean IA, Emich M, Fritzer-Szekeres M, Litschauer B, Graf S, Saemann MD, Strametz-Juranek J (2017) Sports and HDL-quality reflected by serum amyloid A and surfactant protein B. Int J Med Sci 14(11):1040-1048

12. Kotani K, Caccavello R, Sakane N, Yamada T, Taniguchi N, Gugliucci A (2011) Influence of physical activity intervention on circulating soluble receptor for advanced glycation end products in elderly subjects. J Clin Med Res 3(5):252-257 
13. Choi KM, Han KA, Ahn HJ, Hwang SY, Hong HC, Choi HY, Yang SJ, Yoo HJ, Baik SH, Choi DS, Min KW (2012) Effects of exercise on sRAGE levels and cardiometabolic risk factors in patients with type 2 diabetes: a randomized controlled trial. J Clin Endocrinol Metab 97(10):3751-3758

14. Harriss DJ, Atkinson G (2015) Ethical standards in sport and exercise science research: 2016 update. Int J Sports Med 36(14):1121-1124

15. Du Bois D, Du Bois EF (1989) A formula to estimate the approximate surface area if height and weight be known. 1916. Nutrition 5(5):303-311 (discussion 312-313)

16. Luevano-Contreras C, Chapman-Novakofski K (2010) Dietary advanced glycation end products and aging. Nutrients 2(12):1247-1265

17. Bengmark $S$ (2006) Impact of nutrition on ageing and disease. Curr Opin Clin Nutr Metab Care 9(1):2-7

18. Basta G, Lazzerini G, Del Turco S, Ratto GM, Schmidt AM, De Caterina R (2005) At least 2 distinct pathways generating reactive oxygen species mediate vascular cell adhesion molecule-1 induction by advanced glycation end products. Arterioscler Thromb Vasc Biol 25(7):1401-1407

19. Prasad K (2014) Low levels of serum soluble receptors for advanced glycation end products, biomarkers for disease state: myth or reality. Int J Angiol 23(1):11-16

20. Raposeiras-Roubin S, Rodino-Janeiro BK, Paradela-Dobarro B, Grigorian-Shamagian L, Garcia-Acuna JM, Aguiar-Souto P, Jacquet-Hervet M, Reino-Maceiras MV, Gonzalez-Juanatey JR, Alvarez E (2013) Fluorescent advanced glycation end products and their soluble receptor: the birth of new plasmatic biomarkers for risk stratification of acute coronary syndrome. PLoS ONE 8(9):e74302

21. Jensen LJ, Flyvbjerg A, Bjerre M (2015) Soluble receptor for advanced glycation end product: a biomarker for acute coronary syndrome. Biomed Res Int 2015:815942

22. Al Rifai M, Schneider AL, Alonso A, Maruthur N, Parrinello CM, Astor BC, Hoogeveen RC, Soliman EZ, Chen LY, Ballantyne CM, Halushka MK, Selvin E (2015) sRAGE, inflammation, and risk of atrial fibrillation: results from the Atherosclerosis Risk in Communities (ARIC) study. J Diabetes Complicat 29(2):180-185

23. Jiao L, Taylor PR, Weinstein SJ, Graubard BI, Virtamo J, Albanes D, Stolzenberg-Solomon RZ (2011) Advanced glycation end products, soluble receptor for advanced glycation end products, and risk of colorectal cancer. Cancer Epidemiol Biomark Prev 20(7):1430-1438

24. Jiao L, Weinstein SJ, Albanes D, Taylor PR, Graubard BI, Virtamo J, Stolzenberg-Solomon RZ (2011) Evidence that serum levels of the soluble receptor for advanced glycation end products are inversely associated with pancreatic cancer risk: a prospective study. Cancer Res 71(10):3582-3589

25. Goon JA, Aini AH, Musalmah M, Anum MY, Nazaimoon WM, Ngah WZ (2009) Effect of Tai Chi exercise on DNA damage, antioxidant enzymes, and oxidative stress in middle-age adults. J Phys Act Health 6(1):43-54

26. Danzig V, Mikova B, Kuchynka P, Benakova H, Zima T, Kittnar O, Skrha J, Linhart A, Kalousova M (2010) Levels of circulating biomarkers at rest and after exercise in coronary artery disease patients. Physiol Res 59(3):385-392 